\title{
ADSORPTION STUDY OF CRYSTAL VIOLET DYE ONTO Morus nigra L. (MULBERRY TREE) LEAVES POWDER: EQUILIBRIUM, KINETICS AND THERMODYNAMICS STUDY
}

\author{
FAIROOZ AHMAD KHAN ${ }^{\mathrm{a}}$, ABDUL AHAD ${ }^{\mathrm{b}}$, SAMREEN FATEMA ${ }^{\mathrm{c}}$ AND MAZAHAR \\ FAROOQUI ${ }^{\mathrm{d} 1}$
}

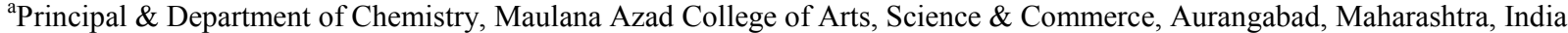

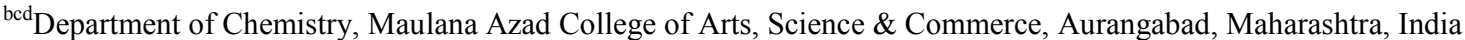

\begin{abstract}
The biosorbents were produced by grinding mulberry leaves to give mulberry leaves powder (MLP) and was utilized for the removal of crystal violet (CV) dye from aqueous solution. To study the effect of various parameters like contact time, concentration, temperature etc batch mode experiments were carried out. Mulberry leaves powder (MLP) was characterized by using Fourier transform infrared spectroscopy (FTIR). The isotherm data fit to some extent into the Langmuir isotherm than that of Freundlich and Temkin isotherms for linear models while as kinetic data fit best to pseudo-second order kinetic model. Intraparticle diffusion studies indicate that more than one mechanism influenced the adsorption process. Gibb's free energy -3.29728 to $\mathbf{- 1 . 2 0 5 9 9}$ for (MLP) indicated spontaneous process. Also the enthalpy changes of $-19.232 \mathrm{KJ} \mathrm{mol}^{-1}$ of $\mathrm{MLP}^{-19}$ indicated exothermic process. Uptake efficiency $(>95 \%)$ recorded at an equilibrium time of 30 minutes shows that MLP was fast and effective adsorbents for the removal of aqueous crystal violet (CV) dye.
\end{abstract}

KEYWORDS: Mulberry Leaves Powder, Crystal Violet, Isotherms, Kinetics, Thermodynamics

The untreated disposals into the water bodies cause major problem to the environment including flora, fauna and human beings (Bhatnagar et al., 2014). The disposal of dyes and pigments is mainly contributed by many textile industries, cosmetic mills, plastic mills, paper mills, pulp mills, distilleries and tanneries and are prominently responsible for disposal of huge amount of dyes and pigments disposing these effluents untreated proportion (Guo et al., 2014). These disposed dyes and pigments are strongly colored and affect the environment especially aquatic life even at low doses as these effluents block the penetration of sunlight and thus affecting the photosynthesis of aquatic plants (Kagalkar et al., 2010). It is estimated that more than 10,000 dyes with an annual production of greater than $7 \times 10^{5}$ metric tons worldwide are commercially available and $5-10 \%$ of this dye stuff is lost in the industrial effluents (Sine, 2003). In this present work the crystal violet $(\mathrm{CV})$ dye which is a synthetic cationic dye that transmits violet color in aqueous solution is taken as a model dye. It is widely useful in the textile industry (for dying cotton, wool, nylon, silk etc), printing inks production, and veterinary medicine (as dermatological agent) (Adak et al., 2005). Crystal violet dye also destroys cells, binds to DNA, and could cause gene mutation and cancer (Sabnis, 2010).
Therefore, there is a need of their removal from wastewater before disposal.

The azo dyes have a complex structure and are considered electron deficient xenobiotic compounds, since these characteristics make these dyes resistant to degradation in wastewaters and thus their treatment is a great challenge. The use of conventional treatment methods such as biological degradation, chemical oxidation, coagulation, flocculation, precipitation, membrane filtration, irradiation, ion exchange, ozonation, and solvent extraction have been investigated with changeable degree of success in dye removal (Noorimotlagh et al., 2019). These methods have certain disadvantages like high investment and operating costs, inefficiency in dye removal and thus there is a need for appropriate treatment of wastewater. Adsorption is one of the simple and economical alternative as new materials of low cost and high efficacy are available for this process, therefore remains one of the most widespread treatment technique (Harrache et al., 2019). Agricultural bio-wastes contain high carbonaceous contents (cellulose, lignin and hemicelluloses) and thus have high affinity for organic molecules, therefore being continuously explored for removal of dyes from wastewaters due to their abundance. These biomaterials contain favourable 
physical and chemical characters therefore requires no or little processing before use (Rangabhashiyam et al., 2013). The plant wastes like wool fiber and cotton fiber, peanut shell, almond shell, hazelnut shell, algal biomass, fruit stones, plum kernels, banana pith, chitosan, neem husk, tamarind fruit shell, coconut tree sawdust, rice husk, olive stones, plum kernels, palm tree cobs, date pits, fruit stones, cassava peel and sugarcane bagasse have been used as low cost adsorbents. The cost of these biomaterials is negligible compared with the cost of activated carbon or ion-exchange resins. These biomaterials are used to remove various dyes like crystal violet (CV) dye. Some low cost biomaterials used as adsorbents are potato peel (Lairini et al., 2017), rice straw (Abd-Elhamid et al., 2020), jute \& sunnhemp (Hussain et al., 2010), juglans regia leaves (Shah et al., 2021), cajanuscajan (red gram) seed husk (Jirekar et al., 2015), husk of green gram (Phaseolus aureus) seed (Jirekar et al. 2014), Cassia siamea (CS), Albizia labbeck (AL), Nerium indicum (NI), Durauta erecta (DE), and potato husk (PH) (Taher et al., 2012), green peas shell (Dandge et al., 2016), masoor seed husk (Jirekar and Farooqui, 2013), black gram seed husk (Jirekar et al., 2015), spines of Taxus bacata (Dar et al., 2011), Vigna unguiculata seed husk powder (Jirekar et al., 2016), elephant grass (Menkiti et al., 2018), bael bark (Kadam and Farooqui, 2018) etc.

The plant leaves contain certain constituents like polyphenols, lignin, pigments and protein making it suitable to provide active sites for binding dyes (Abadian et al., 2015). Morus nigra L.(black mulberry) belongs to flowering plant species in the family Moraceae. It is native to southwestern Asia and the lberian peninsula; however it is also cultivated in Kashmir India as a feed for cattles like sheep etc and its fruits for eatable juice. The aim of our work is to find out the efficient, low cost adsorbents to manage wastewater so we used mulberry leaves to convert them into mulberry leaves powder (MLP) for the adsorption of crystal violet (CV) dye from aqueous solution.

\section{EXPERIMENT}

\section{Materials}

All the chemicals used in this research work were of analytical grade and used as received. Crystal violet (CV) (99.9 \%) Sigma-Aldrich), mulberry leaves powder, leaves of which were collected in local native village (first author) (Dungdara Dawlatpora Kreeri Baramulla Kashmir India).

\section{Instrumentation}

Water distillation plant, UV/Vis. Spectrophotometer (Elico double beam SL 244.), pH meter (Equip- Tronics EQ-610), magnetic hot plate stirrer (Macro Scientific Works (R),10A/UA, Jawahar Nagar, Delhi- 110007.), electronic balance, centrifuge,(eltek multispin TC 650 F.), and grinder machine (Usha Mixer Grinder (MG-3576) 750 Watt.) are used throughout the experimental investigations.

\section{Preparation of Leaf Powder}

Mulberry leaves were collected from Dungdara Dawlatpora Kreeri Baramulla J\&K India where huge number of Mulberry trees exist. These leaves were kept under sun for five days for drying after extensive washing with tap water and then distilled water to remove Suspended impurities. Dried leaves were crushed into fine powder by using grinder. The MLP were washed with distilled water again and again until it became free from dust and color. Dirt free MLP was sun dried for five days and then in an oven at $65{ }^{\circ} \mathrm{C}$ until it attained constant weight. For further use in experiments, the adsorbent was stored in an air tight voils.

\section{Adsorption Process}

Variation of the color of crystal violet (CV) dye in an aqueous solution by MLP adsorbent under continuous stirring on magnetic stirrer was recorded and studied by UV/Vis. Spectrophotometer. We carried out the experiments by placing $20 \mathrm{ml}$ of the crystal violet dye solution in a $100 \mathrm{ml}$ glass beaker at various initial dye concentrations $(5.4,12.8,17.3,27.2,33.3,43.9$ and 58.7 ppm). Distinctive amounts of adsorbent (MLP) (0.05$0.30 \mathrm{mg}$ ) and the effect of contact time were demonstrated at different time intervals $(05,10,20,30$, 40, 50 and $60 \mathrm{~min}$ ). The salinity was checked by adding $\mathrm{KCl}$ and $\mathrm{CaCl}_{2}$ to the dye solution in the range of $0.05-$ $0.30 \mathrm{~g}$, temperature was diversed from $25{ }^{\circ} \mathrm{C}-65{ }^{\circ} \mathrm{C}$ and $\mathrm{pH}$ was considered in acidic medium only at $2.62,2.96$ and 3.35 as base discolourise the crystal violet (CV) dye solution. Finally, suspension was filtered by whatmann's filter paper and crystal violet dye concentration in filterate was determined with the help of spectrophotometer at $581.5 \mathrm{~nm}$ as it is its $\lambda_{\max }$.

The $\mathrm{CV}$ dye percentage removal $(\% R)$ is defined as:

$$
\% R=\frac{C_{0}-C_{t}}{C_{0}}
$$

Where, $C_{o}$ and $C_{t}$ are the initial concentration and the concentration of $\mathrm{CV}$ dye at time $\mathrm{t}$, respectively. 


\section{Characterization}

The characterization of the MLP adsorbent was carried out by a Fourier transform infrared spectroscopy (FT-IR) covering the range from 400 to $4000 \mathrm{~cm}^{-1}$, carried out in Babasaheb Ambedkar Marathwada University Chemistry Dept. Aurangabad India.

The FTIR spectra of MLP is shown in fig. 1. Several peaks were observed from the spectra (Fig. 1), indicating that mulberry leaves powder is composed of various functional groups which are responsible for binding of positively charged crystal violet $(\mathrm{CV})$ dye. The broad absorption peak at $3271.27 \mathrm{~cm}^{-1}$ corresponds to the $\mathrm{O}-\mathrm{H}$ stretching vibration of alcohols, phenols and carboxylic acids as in pectin, cellulose, and lignin, thus showing the presence of "free" hydroxyl groups on the adsorbent surface (Pathania et al., 2017). The broad peak is because of macromolecular association by hydrogen bonding (Pavia et al., 1996). The small three peaks at $3759.26,3714.90$ and 1608.63 are probably due to asymmetric, symmetric and bending vibrations of adsorbed water molecules respectively (Kaur, 2009). The absorption peaks at 2922.16 and $2848.86 \mathrm{~cm}^{-1}$ are attributed to the $(\mathrm{C}-\mathrm{H})$ asymmetric and symmetric stretching vibrations, respectively (Pavia et al 1996). Three weak peaks are found at 2096.62, 2125.56 and $2164.13 \mathrm{~cm}^{-1}$ which can be described as $-\mathrm{C} \equiv \mathrm{C}-$ alkyne band. The peaks at $2258.64 \mathrm{~cm}^{-1}$ with $\mathrm{C} \equiv \mathrm{N}$ stretches show nitrile functional group (Wellesley college, 1875). Peak at 1722.43 represents ester and carboxyl groups with $\mathrm{C}=\mathrm{O}$ stretch (University of Colorado, 1985), the spiky strong peak observed at $1608.63 \mathrm{~cm}^{-1}$ is assigned to $\mathrm{C}=\mathrm{C}$ ring stretch of aromatic rings (Pavia et al., 1996). In addition the band at $1421.54 \mathrm{~cm}^{-1}$ confirm the presence of $\mathrm{C}=\mathrm{C}$ of aromatic rings (Pavia et al., 1996). The presence of alcohols, carboxylic acids, esters and ethers functional groups were observed through $\mathrm{C}-\mathrm{O}$ strong stretch in the absorption band at 1,320-1,000 cm frequency with absorption peaks at 1317.38, 1228.66, 1095.57 and $1014.56 \mathrm{~cm}^{-1}$ (University of Colorado, 1985). Alkene small $=\mathrm{C}-\mathrm{H}$ absorption bend is found strongly in between 1,000 and $650 \mathrm{~cm}^{-1}$ having peaks at $898.83 \mathrm{~cm}^{-1}$.

\section{RESULTS AND DISCUSSION}

The structure of crystal violet (CV) dye is specified in fig.2. The conditions of maximum removal for crystal violet (CV) dye from aqueous solution by given adsorbent (MLP) were initially optimized. For optimization effect of contact time, concentration of dye solution, amount of dose of adsorbents, effect of temperature, effect of salt and effect of $\mathrm{pH}$ were varied to the large extent. The results of above mentioned parameters for crystal violet $(\mathrm{CV})$ dye were summarized in graphs.

\section{Effect of Contact Time}

The effect of the contact time on adsorption of crystal violet $(\mathrm{CV})$ dye by MLP at $\mathrm{pH}$ 6.52, concentration $27.2 \mathrm{mg} / \mathrm{L}$, temperature $24{ }^{\circ} \mathrm{C}$ and dose of adsorbents $0.05 \mathrm{gm} / 20 \mathrm{ml}$ as given in fig. 3 . This graph indicates that initially there was rapid intake of dye by adsorbent and became constant (at equilibrium) after a particular time. Indeed, it is possible because initially all the sites are vacant and get occupied with the passage of time where it shows equilibrium. It is to be noted that at initial stages adsorption rate is high and slows down with the passage of time because of competition of dye molecules for adsorption on adsorbents (Santos and Boaventura, 2016).

\section{Effect of Initial Dye Concentration}

The effect of initial crystal violet (CV) dye concentration was investigated by batch mode experiments at temperature $=27{ }^{\circ} \mathrm{C}$, dose $=0.05 \mathrm{gm} / 20$ $\mathrm{ml}, \mathrm{pH}=6.52$, contact time 30 minutes and the concentration range of $5.4,12.8,17.3,27.2,33.3,43.9$ and $58.7 \mathrm{mg} / \mathrm{L}$ were used as shown in fig.4. The adsorption capacity increased with increase in crystal violet $(\mathrm{CV})$ dye concentration from 2.1 to $20.9 \mathrm{mg} / \mathrm{gm}$. for MLP. This is because at higher concentration there is higher concentration gradient thus greater driving force resulting in higher adsorption capacity (Tan et al., 2008).

\section{Effect of Adsorbent Dose}

The percentage removal of crystal violet $(\mathrm{CV})$ dye as a function of adsorbents dose at equilibrium are presented in fig. 5. It was observed in the figure that the percentage removal of dye was first increased from 98.2 to $98.7 \%$ with an increase in adsorbent dose from 0.05 to $0.15 \mathrm{gm} . / 20 \mathrm{ml}$ and then decreases. The increase in the percentage removal of crystal violet $(\mathrm{CV})$ dye with dose of adsorbents could be attributed to increase in the adsorbent active sites. On the other hand, the adsorption capacity was decreased after a particular dose and may be attributed due to hidening of adsorbent sites.

\section{Effect of Salt of Adsorbent}

The effect of $\mathrm{KCl}$ and $\mathrm{CaCl}_{2}$ dose in the range of $0.05-0.3 \mathrm{gm} . / 20 \mathrm{ml}$ dye solution at temperature $27^{\circ} \mathrm{C}$ on the percentage removal of crystal violet (CV) dye solution $(27.2 \mathrm{mg} / \mathrm{L})$ was studied as shown in fig. 6 and fig. 7.The dose for this observation was taken $0.05 \mathrm{gm}$ separately for 30 minutes. It is clearly shown in figures 
that there is slight variation in the percentage removal of crystal violet (CV) dye by the adsorbent. The graphs shows decrease in percentage removal and may be due to the increase in ionic strength causing screening of surface charges.

\section{Effect of Temperature}

Temperature is one of the important parameters affecting mobility and solubility of dye molecules in aqueous solution. It has also impact on the surface properties of adsorbents. For this investigation the parameters like concentration of dye solution, volume, time and dose of adsorbent were taken same as those in contact time. In this search percentage removal of crystal violet (CV) dye decreases from 90.4 to $79.3 \%$ for MLP as shown in fig. 8 showing exothermic processes.

\section{Effect of pH}

$\mathrm{pH}$ is also one of the important factor that controls the removal of crystal violet (CV) dye by MLP adsorbent. The $\mathrm{pH}$ study was performed at a temperature of $26^{\circ} \mathrm{C}$, dose $0.05 \mathrm{gm}$ and volume $20 \mathrm{ml}$ of dye solution for 30minutes. The result shown in the fig. 9 indicates that MLP adsorbent showed good removal capacity in basic medium. However it is not investigated in basic medium as base like $\mathrm{NaOH}$ discolourise the crystal violet (CV) dye solution.

\section{Adsorption Isotherms}

To study the relationship between the quantity of adsorbed adsorbate ( $\mathrm{mg}$ ) and the adsorbent (gm), adsorption isotherm models were used. The most commonly used isotherm models studied also here are Langmuir (Langmuir, 1918), Freundlich (Freundlich, 1906) and Temkin (Temkin and Pyzhev, 1940). The Langmuir adsorption isotherm is significant for monolayer adsorption and considers that there are identical sites on the adsorbent surface. The Langmuir isotherm is represented by the following linearized forms as given in Eq.(2)

$\frac{1}{q_{e}}=\frac{1}{q_{o}}+\frac{1}{q_{o} b C_{e}}$

Where, $\mathrm{C}_{\mathrm{e}}=$ equilibrium dye concentration $(\mathrm{mg} / \mathrm{L}), \mathrm{q}_{\mathrm{e}}=$ amount of $\mathrm{CV}$ dye adsorbed per unit mass at equilibrium ( $\mathrm{mg} / \mathrm{gm}), \mathrm{q}_{\mathrm{o}}=$ adsorption capacity $(\mathrm{mg} / \mathrm{gm}$.) and $\mathrm{b}=$ Langmuir constant $(\mathrm{L} / \mathrm{mg})$. These values are obtained from the slope and intercept by plotting a graph between ' $1 / \mathrm{q}_{\mathrm{e}}$ ' versus ' $1 / \mathrm{C}_{\mathrm{e}}$ ' (fig. 10). The Equilibrium factor or separation factor ' $\mathrm{R}_{\mathrm{L}}$ ' was used to express important characteristics of Langmuir equilibrium isotherm (Hall et al., 1966), which is given as below:
$R_{L}=\frac{1}{1+b C_{O}}$

Where, $\mathrm{C}_{\mathrm{o}}=$ initial dye concentration $(\mathrm{mg} / \mathrm{L})$. Four ' $\mathrm{R}_{\mathrm{L}}$ ' values are possible for any adsorption: $\mathrm{R}_{\mathrm{L}}>1$ (unfavourable), $\mathrm{R}_{\mathrm{L}}=1$ (linear), $\mathrm{R}_{\mathrm{L}}=0$ (irreversible) and 0 $<\mathrm{R}_{\mathrm{L}}<1$ (favourable) (Taher, 2012).The Langmuir constants and $R_{L}$ values are given in table 1 where $R_{L}$ values lie between 0 and 1 indicating Langmuir isotherm is favourable.

Freundlich adsorption isotherm describes multilayer adsorptions on heterogeneous adsorbent surface with different functional groups showing different adsorbent-adsorbate interactions and its linear form is expressed as:

$\ln q_{e}=\ln K_{f}+\frac{1}{n} \ln C_{e}$

Where, $K_{f}$ is the Freundlich constant $[\mathrm{mg} / \mathrm{g}$ $\left.(\mathrm{L} / \mathrm{gm})^{1 / \mathrm{n}}\right]$ related to bonding energy and ' $\mathrm{n}$ ' is the heterogeneity factor. The plot of lnqe against $\operatorname{lnCe}$ gives a straight line with slope and intercepts (fig.11). The value of ' $n$ ' lies between 1 to 10 indicates favourable adsorption. These Freundlich constants are also summarized in table 1.

The Temkin model considered the effects of interaction of the adsorbate and the adsorbing species (Temkin and Pyzhev, 1940). It is because of these interactions the heat of adsorption of all the molecules in the layer would decrease linearly rather than logarithmically with coverage due to adsorbate-adsorbent interactions (Temkin and Pyzhev, 1940), the linearized form of equation is as:

$q_{e}=B \ln A_{T}+B \ln C_{e}$

$B=\frac{R T}{b_{T}}$

Where, $b=$ Temkin constant related to heat of sorption $(\mathrm{J} / \mathrm{mol}), \mathrm{A}=$ Temkin isotherm constant $(\mathrm{L} / \mathrm{gm})$, $\mathrm{R}=$ gas constant $(8.314 \mathrm{~J} / \mathrm{mol} . \mathrm{K})$ and $\mathrm{T}=$ absolute temperature (K). By plotting a graph between qe versus $\ln C_{e}$ (fig.12) gives a straight line with slope and intercept from which constants can be determined as listed in table 1.

\section{Kinetic Studies}

Adsorption kinetics of crystal violet (CV) dye by given adsorbent was also evaluated and analysed by using pseudo-first-order, pseudo-second-order and intra-particle diffusion models in order to explore the mechanism and the momentary behavior of the dye adsorption process. 


\section{Pseudo-First-Order and Pseudo-Second-Order Kinetic Models}

The linearized integral form of the pseudo-firstorder kinetic model developed by Lagergren is generally expressed as (Lagergren, 1898):

$\log \left(q_{e}-q_{t}\right)=\log q_{e}-\frac{K_{1}}{2.303} t$

Where, $\mathrm{k}_{1}=$ rate constant of pseudo-first-order adsorption $\left(\right.$ min. $\left.^{-1}\right), \mathrm{q}_{\mathrm{e}}=$ amounts of crystal violet $(\mathrm{CV})$ dye adsorbed by MLP at equilibrium $(\mathrm{mg} / \mathrm{gm})$ and $\mathrm{q}_{\mathrm{t}}=$ amount of CV dye adsorbed by MLP at time ' $\mathrm{t}$ ' (mg/gm). Plot of $\log \left(\mathrm{q}_{\mathrm{e}}-\mathrm{q}_{\mathrm{t}}\right)$ against time (t) (fig. 13) resulted with lower correlation coefficients as mentioned in table 2 . First order kinetic model showed poor fitting because of having lower correlation coefficients and the values calculated for ' $\mathrm{q}_{\mathrm{e}}$ ' from the graph showed an enormous deviation with the experimental data. Experimental data were further investigated by using pseudo-second-order kinetic model (Weber and Morris, 1963) having linearized form as:

$\frac{t}{q_{t}}=\frac{1}{K_{2} \times q_{e}^{2}}+\frac{1}{q_{e}} \times t$

Where, $\mathrm{k}_{2}=$ rate constant for pseudo-secondorder adsorption $\left(\mathrm{g} \mathrm{mg}^{-1} \mathrm{~min}^{-1}\right)$. The plot of ' $\mathrm{t} / \mathrm{q}_{\mathrm{t}}$ ' against ' $t$ ' (fig. 14) of Eq. (7) gives a linear line with slope and intercept from which ' $\mathrm{q}_{\mathrm{e}}$ ' and ' $\mathrm{k}_{2}$ ' can be calculated. The graph shows that experimental data had a good fit to Pseudo-second-order kinetic model with higher values of correlation coefficient $\left(\mathrm{R}^{2}=1\right)$.

To calculate the initial sorption rate $v_{0}$, constant $\mathrm{K}_{2}$ is used at $\mathrm{t} \rightarrow 0$, as follows:

$v_{o}=K_{2} \times q_{e}^{2}$

Thus the rate constants ' $\mathrm{K}_{2}$ ', calculated equilibrium uptakes ' $\mathrm{q}_{\mathrm{e}}$ ', the initial sorption rate ' $v_{\mathrm{o}}$ ' and the corresponding correlation coefficients ' $\mathrm{R}^{2}$, of crystal violet dye for MLP adsorbent for the given concentration were determined and presented also in Table 2. The elevated agreement between calculated and experimental values proves that the adsorption of crystal violet dye onto MLP perfectly followed pseudo second order kinetic model.

\section{Intraparticle Diffusion Model}

Intraparticle diffusion model was proposed by Weber and Morris (Weber and Morris, 1963) and is used for identifying the mechanism of adsorption for design purpose. There are large numbers of adsorption processes where amount of adsorbate adsorbed varies almost proportionately with ' $t$ ' 1 ' rather than with the contact time (Dawood et al., 2014).

$K_{i d} q_{t}=t^{0.5}+I$

Where, $\mathrm{q}_{\mathrm{t}}=$ amount of CV dye adsorbed at time $\mathrm{t}, \mathrm{t}^{1 / 2}=$ square root of time and $\mathrm{K}_{\mathrm{id}}=$ rate constant for intra-particle diffusion $\left(\mathrm{mg} / \mathrm{g} \min ^{1 / 2}\right)$. I $(\mathrm{mg} / \mathrm{g})$ is a constant giving an idea about the thickness of the boundary layer. $\mathrm{K}_{\mathrm{id}}$ is determined from the slope of the linear equation where ' $\mathrm{q}_{\mathrm{t}}$ ' is plotted against ' $\mathrm{t}$ ', , (fig.15) and constants are given in table 2 .

\section{Thermodynamic Studies}

Thermodynamic parameters are very important in order to understand the the effect of temperature on adsorption process. The thermodynamic study for adsorption process was carried out at different temperatures from $298.15 \mathrm{~K}$ to $338.15 \mathrm{~K}$ and Van't Hoff equation (Ijagbemi et al., 2009; Khan et al, 2021) as given below was applied to evaluate the thermodynamic parameters like the $\Delta \mathrm{G}^{0}, \Delta \mathrm{H}^{\mathrm{o}}$ and $\Delta \mathrm{S}^{\mathrm{o}}$.

$\ln K_{c}=\frac{\Delta S^{o}}{R}-\frac{\Delta H^{o}}{R T}$

Where, $\mathrm{K}_{\mathrm{c}}=$ equilibrium constant for sorption, $\mathrm{R}=$ universal gas constant $(8.314 \mathrm{~J} / \mathrm{mol} . \mathrm{K}), \mathrm{T}=$ absolute temperature $(\mathrm{K})$. The value of $\Delta \mathrm{H}^{\circ}$ and $\Delta \mathrm{S}^{\circ}$ can be calculated from the slope and intercept by plotting a graph between ' $\ln K_{c}$ ' and ' $1 / T$ ' (fig. 16). The $K_{c}$ value was determined with the help of following relation:

$\mathrm{K}_{\mathrm{c}}=\frac{\mathrm{q}_{\mathrm{e}}}{\mathrm{C}_{\mathrm{e}}}$

Where, ' $\mathrm{q}_{\mathrm{e}}$ ' $\left(\mathrm{mg} \mathrm{gm}{ }^{-1}\right)$ and ' $\mathrm{C}_{\mathrm{e}}$ ' $\left(\mathrm{mg} \mathrm{L}^{-1}\right)$ have usual meanings as described in the paper.

Knowing $\Delta \mathrm{H}^{\circ}$, the thermodynamic parameters for adsorption process like $\Delta \mathrm{G}^{\mathrm{o}}$, and $\Delta \mathrm{S}^{\mathrm{o}}$ can also be obtained by using the following relations:

$\Delta G^{o}=-R T \ln K_{c}$

$\Delta G^{o}=\Delta H^{o}-T \Delta S^{o}$

The estimated thermodynamic parameters $\left(\Delta \mathrm{G}^{0}\right.$, $\Delta \mathrm{H}^{\circ}$ and $\Delta \mathrm{S}^{\circ}$ ) and $\mathrm{R}^{2}$ are presented in table 3.The enthalpy change $\left(\Delta \mathrm{H}^{0}\right)$ for the adsorption of crystal violet (CV) dye onto MLP signifies that MLP adsorbent shows exothermic adsorption process. The $\Delta G^{o}$ value was negative at all considered temperatures indicating that the adsorption of crystal violet (CV) dye by MLP is feasible and spontaneous. Similarly, $\Delta \mathrm{S}^{\circ}$ is negative for MLP adsorbent for adsorption of crystal violet (CV) dye and may be due to the decrease in randomness of dye molecules at interface. 
KHAN ET AL.: ADSORPTION STUDY OF CRYSTAL VIOLET DYE ONTO Morus nigra L. (MULBERRY TREE)....

Table 1: Langmuir, Frundlich and Temkin isotherm data for crystal violet (CV) dye using MLP adsorbent

\begin{tabular}{|c|c|c|c|c|}
\hline \multirow{2}{*}{ Langmuir } & $\mathbf{Q}_{\mathbf{0}}(\mathbf{m g} / \mathbf{g m} \mathbf{)}$ & $\mathbf{b} \mathbf{( \mathbf { l } / \mathbf { m g } )}$ & $\mathbf{R}_{\mathbf{L}}$ & $\mathbf{R}^{\mathbf{2}}$ \\
\cline { 2 - 5 } & $\mathbf{5 0}$ & 0.2666 & 0.0599 & 0.9332 \\
\hline \multirow{2}{*}{ Frundlich } & $\mathbf{1 / n}$ & $\mathbf{N}$ & $\mathbf{K}_{\mathbf{f}}$ & $\mathbf{R}^{\mathbf{2}}$ \\
\cline { 2 - 5 } & 0.517 & 1.934 & 8.2978 & 0.79246 \\
\hline \multirow{2}{*}{ Temkin } & $\mathbf{A}_{\mathbf{T}}$ & $\mathbf{B}$ & $\mathbf{b}_{\mathbf{T}}$ & $\mathbf{R}^{\mathbf{2}}$ \\
\cline { 2 - 5 } & 9.2415 & 4.497 & 554.913 & 0.88604 \\
\hline
\end{tabular}

Table 2: Kinetic data for crystal violet (CV) dye adsorption onto MLP adsorbent

\begin{tabular}{|c|c|c|c|c|}
\hline \multirow{2}{*}{ Pseudo-first-order } & $\mathbf{R}^{\mathbf{2}}$ & $\mathbf{K}_{\mathbf{1}}$ & \multicolumn{2}{|c|}{$\mathbf{q}_{\mathrm{e}}$} \\
\cline { 2 - 5 } & 0.6695 & 0.1589 & \multicolumn{2}{|c|}{2.716} \\
\hline \multirow{2}{*}{ Pseudo-second-order } & $\mathbf{R}^{\mathbf{2}}$ & $\mathbf{q}_{\mathrm{e}}$ & $\mathbf{K}_{\mathbf{2}}$ & $\mathbf{V}_{\mathbf{0}}$ \\
\cline { 2 - 4 } & 1 & 10.7422 & 0.5127 & 59.1715 \\
\hline \multirow{2}{*}{ Intraparticle diffusion } & $\mathbf{R}^{\mathbf{2}}$ & Intercept (I) & \multicolumn{2}{|c|}{ Slope } \\
\cline { 2 - 5 } & 0.8157 & 10.338 & \multicolumn{2}{|c|}{0.0543} \\
\hline
\end{tabular}

Table 3: Thermodynamic parameters

\begin{tabular}{|c|c|c|c|c|}
\hline Temperature(k) & $\Delta \mathbf{G}=-\mathbf{R T I n K c}$ & $\mathbf{R}^{\mathbf{2}}$ & $\Delta \mathbf{S}$ & $\Delta \mathbf{H}$ \\
\hline 298.15 & -3.29728 & 0.98785 & -0.05309 & -19.2322 \\
\cline { 1 - 2 } 308.15 & -2.98302 & & & \\
\hline 318.15 & -2.39746 & & & \\
\hline 328.15 & -1.81369 & & & \\
\hline 338.15 & -1.20599 & & & \\
\hline
\end{tabular}

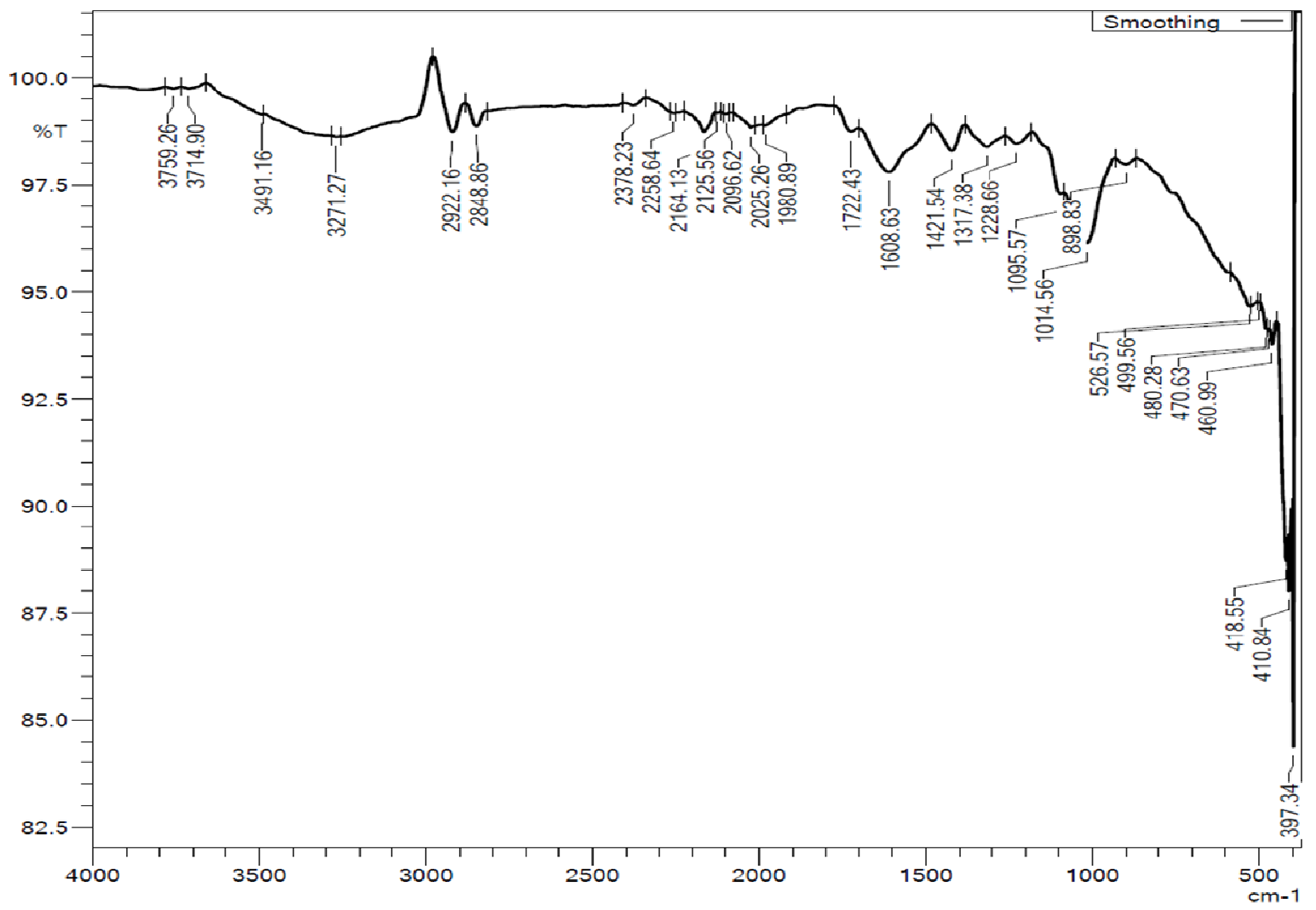

C: $¥$ Program Files $(\times 86) ¥$ LabSolutions $¥ \mathrm{IR} ¥$ Data $¥ 541$ (M.D) 9 JAN 2020 1.ispd

Figure 1: FTIR of CLP 


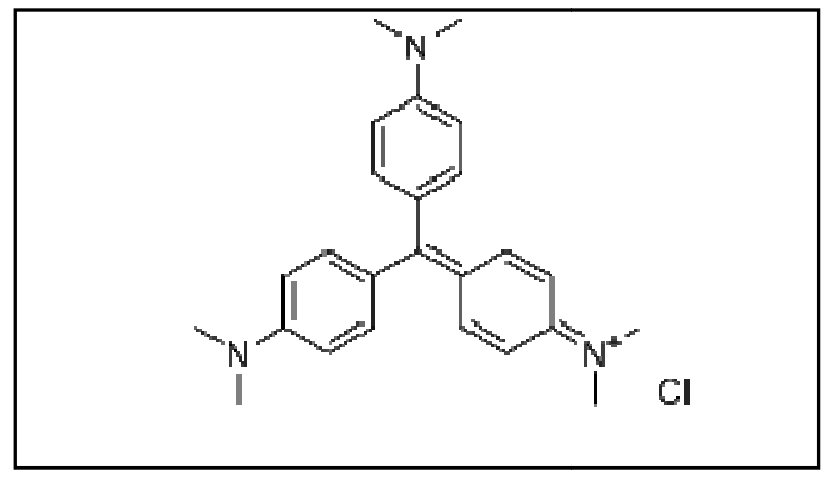

Figure 2: Chemical structure of crystal violet (CV) dye

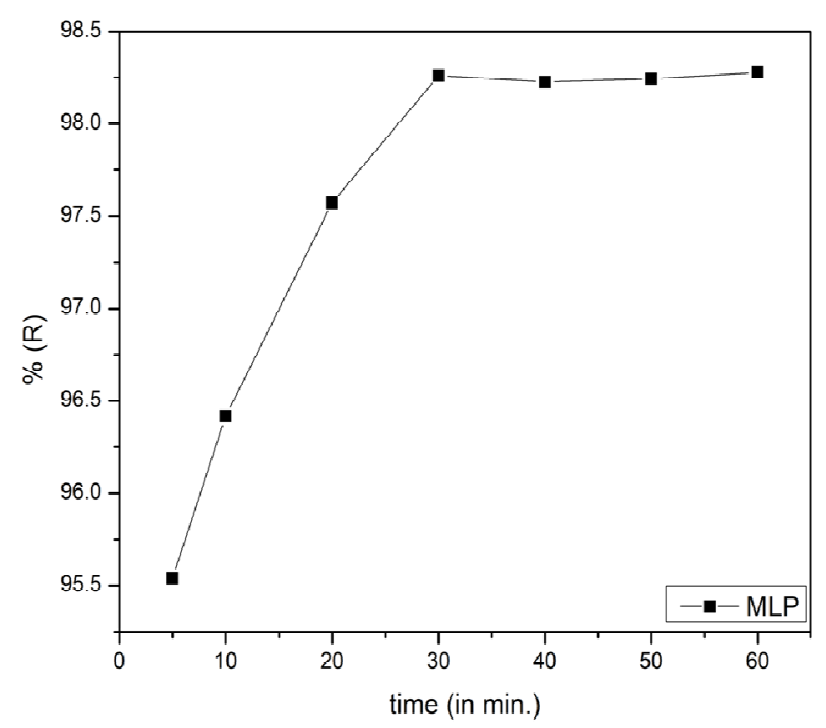

Figure 3: Effect of contact time on CV adsorption.

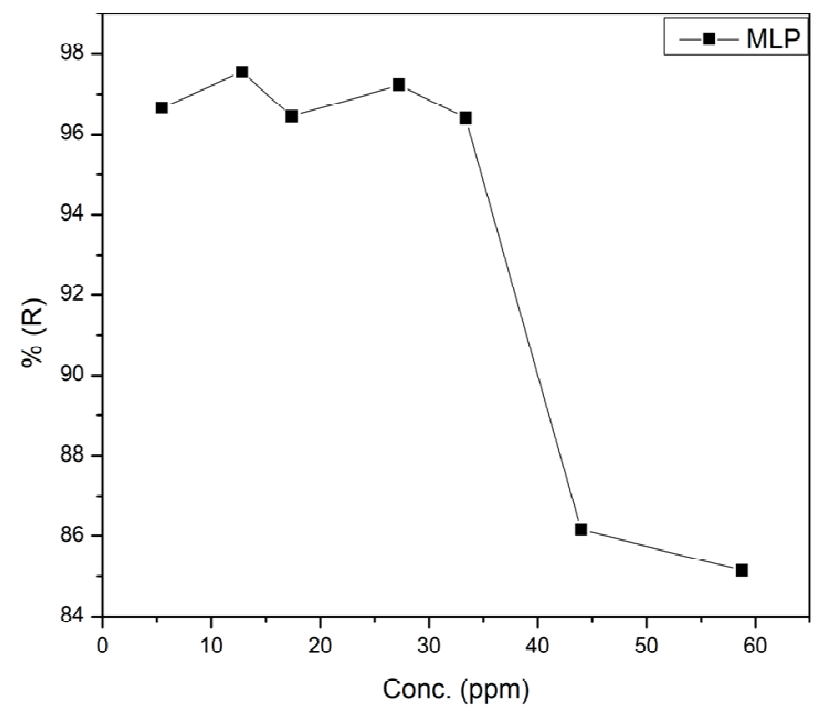

Figure 4: Effect of conc. on CV adsorption

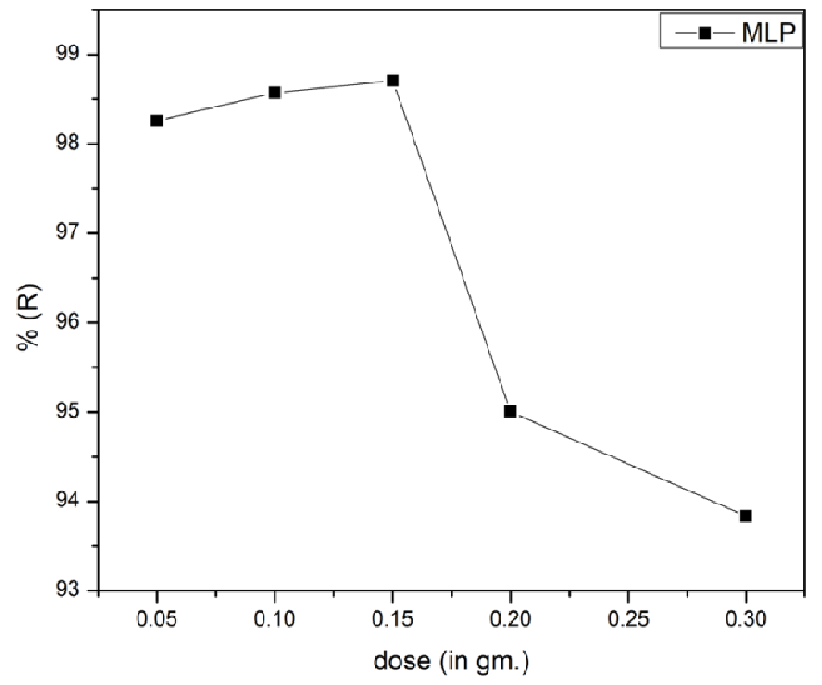

Figure 5: Effect of dose on CV adsorption

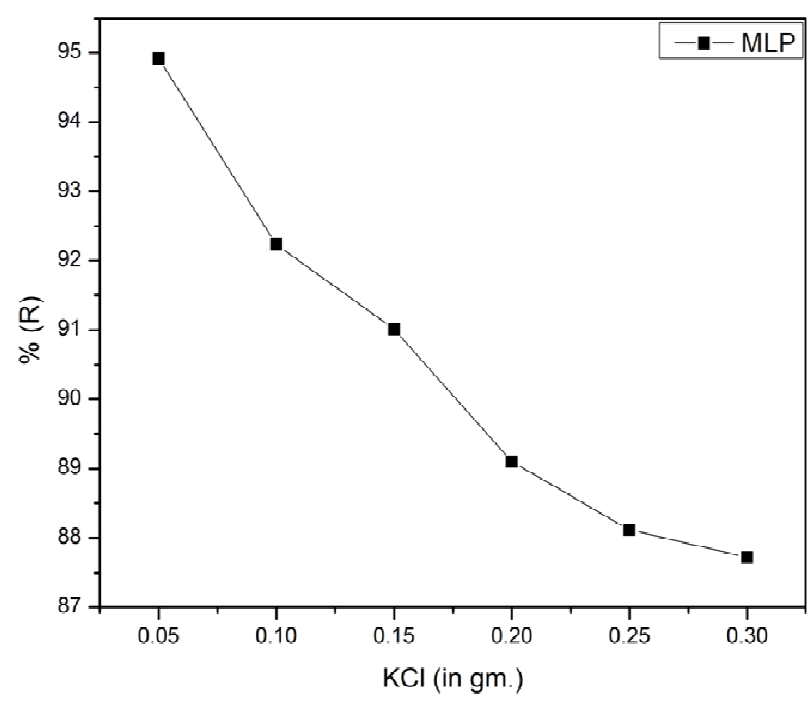

Figure 6: Effect of $\mathrm{KCl}$ on $\mathrm{CV}$ adsorption

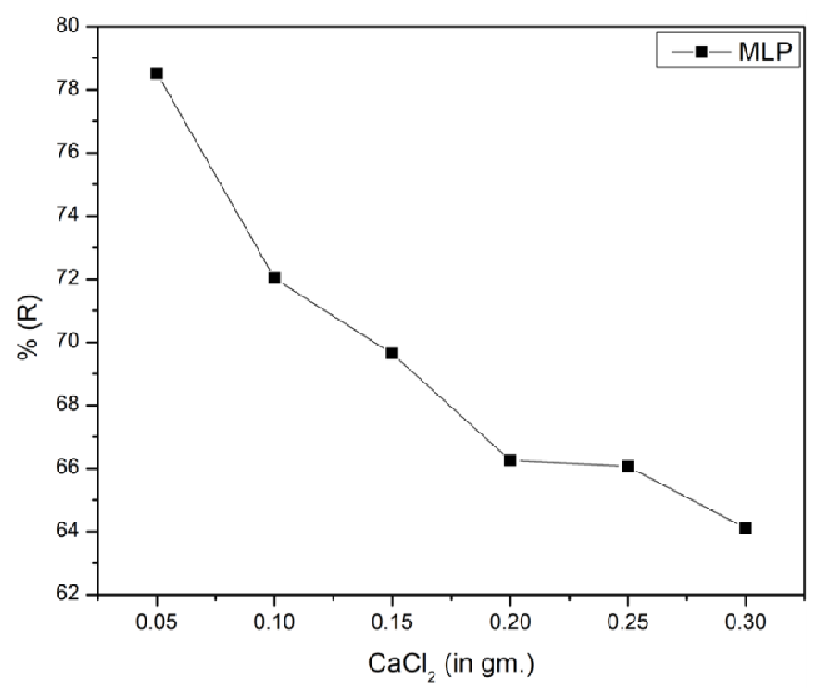

Figure 7: Effect of $\mathrm{CaCl}_{2}$ on $\mathrm{CV}$ adsorption 
KHAN ET AL.: ADSORPTION STUDY OF CRYSTAL VIOLET DYE ONTO Morus nigra L. (MULBERRY TREE)....

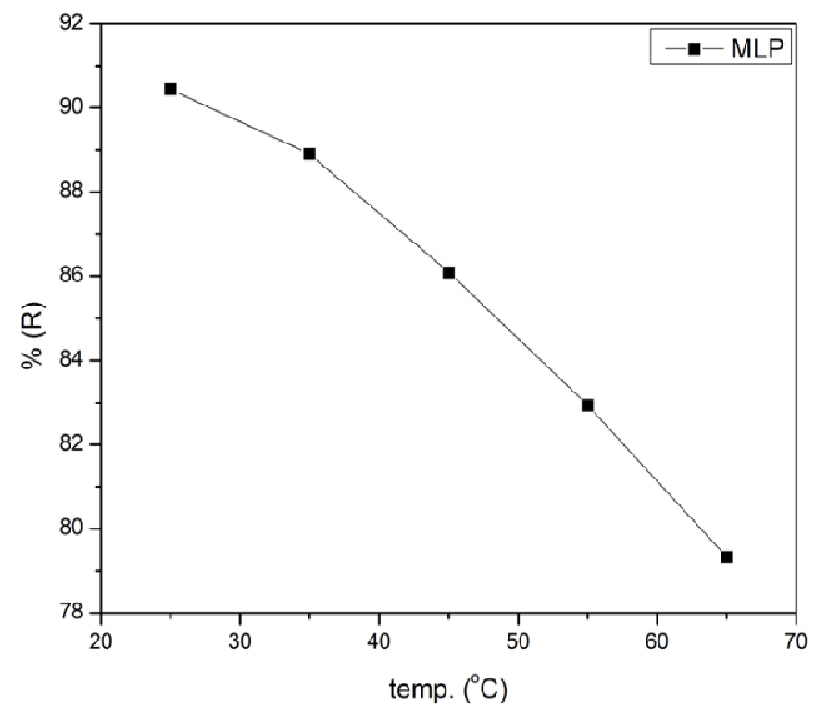

Figure 8: Effect of temp. on CV adsorption

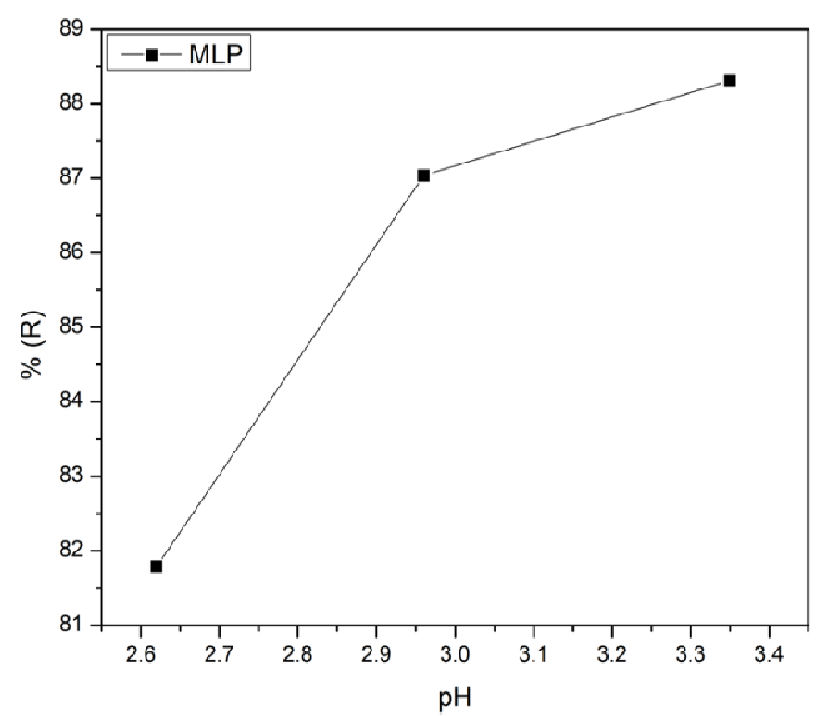

Figure 9: Effect of pH on CV adsorption

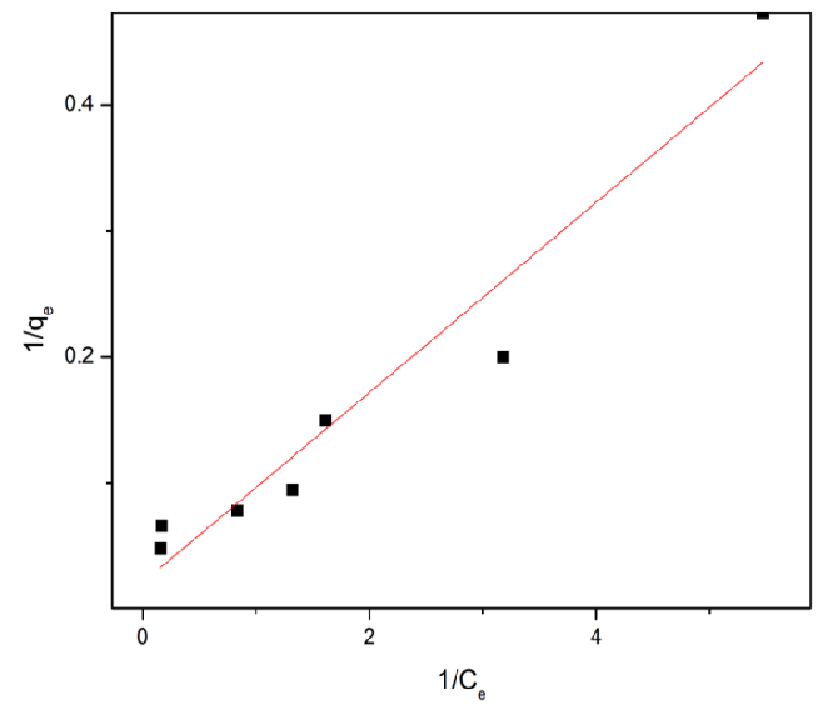

Figure 10: Langmuir isotherm plot of $\mathrm{CV}$ dye

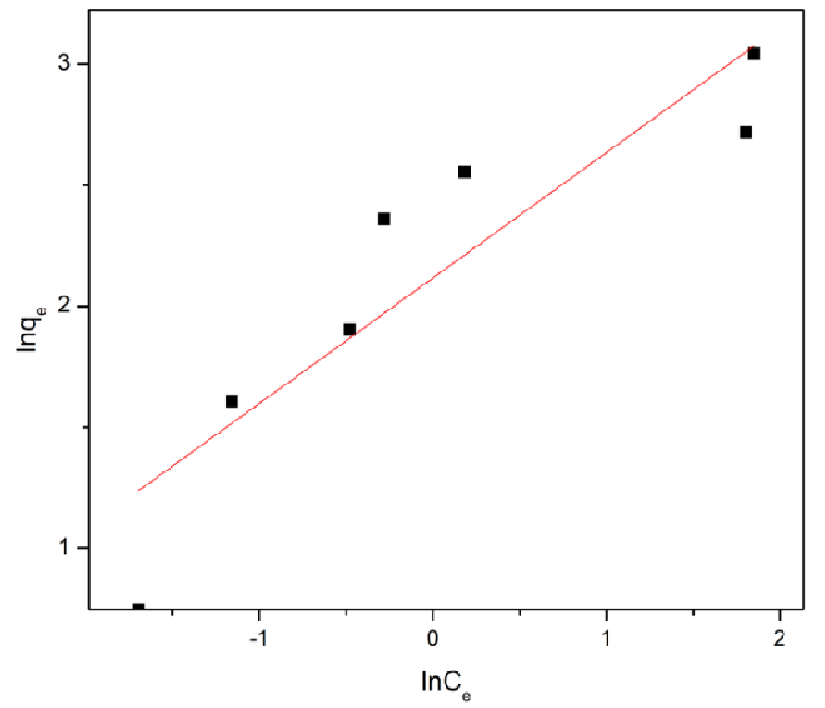

Figure 11: Freundlich isotherm plot of $\mathrm{CV}$ dye

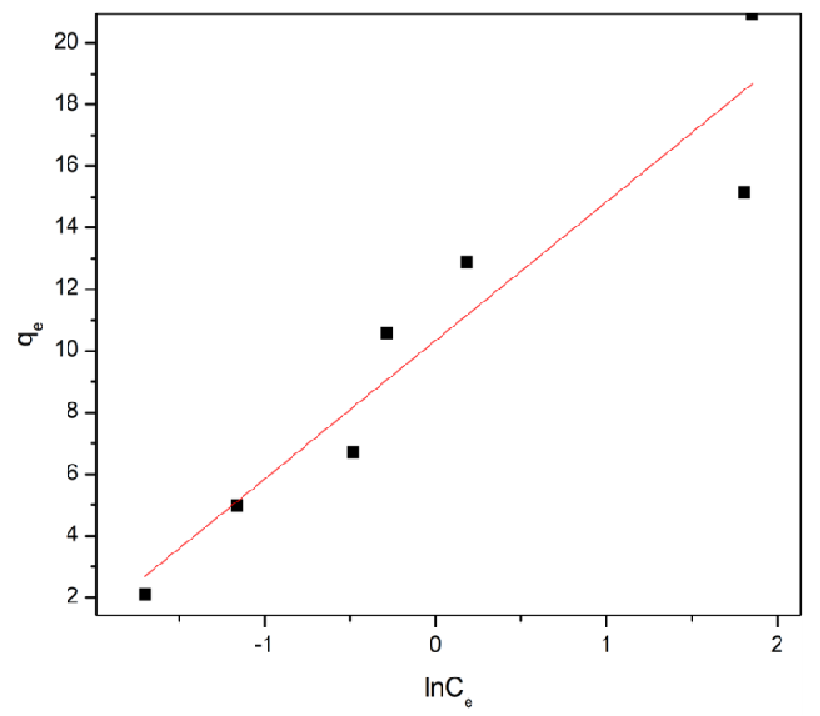

Figure 12: Temkin isotherm plot of CV dye

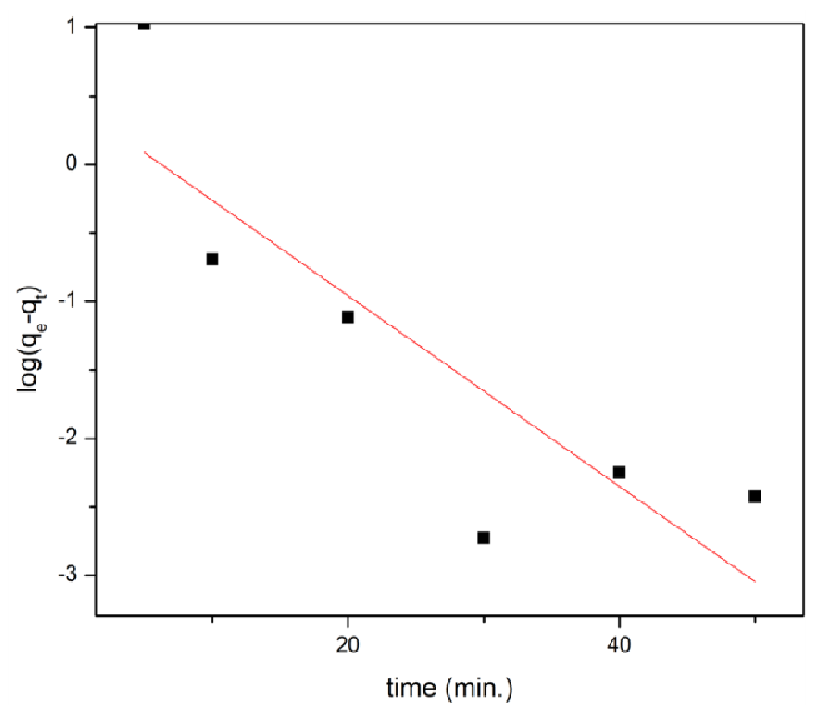

Figure 13: Pseudo first orde kinetic model 


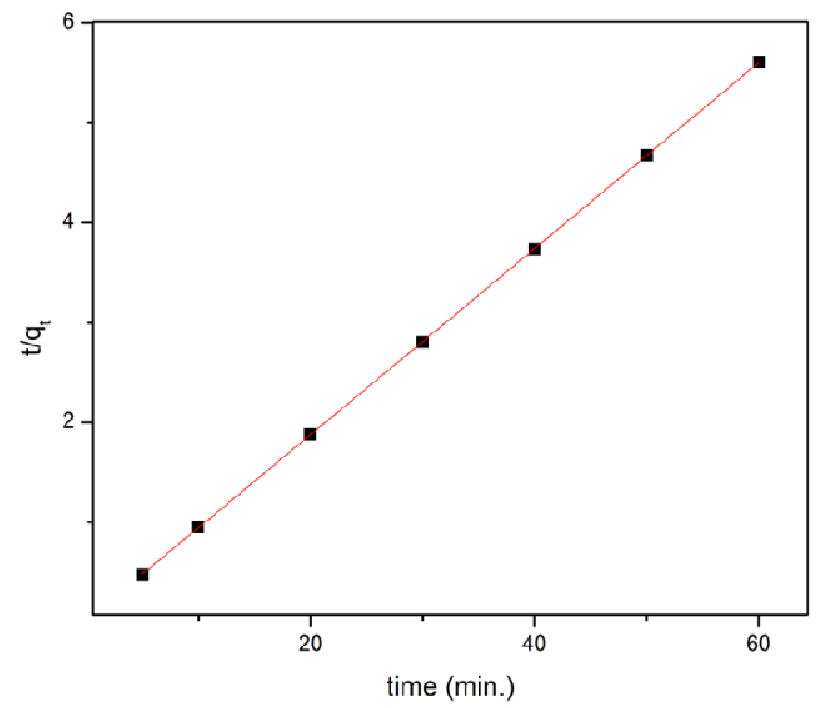

Figure 14: Pseudo second order kinetic model

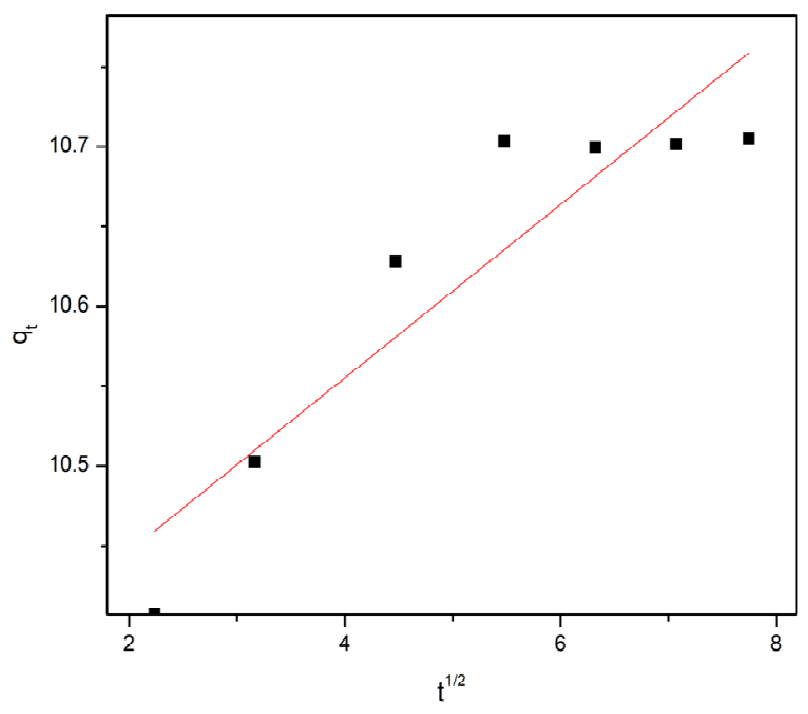

Figure 15: Intraparticle diffusion model (CV)

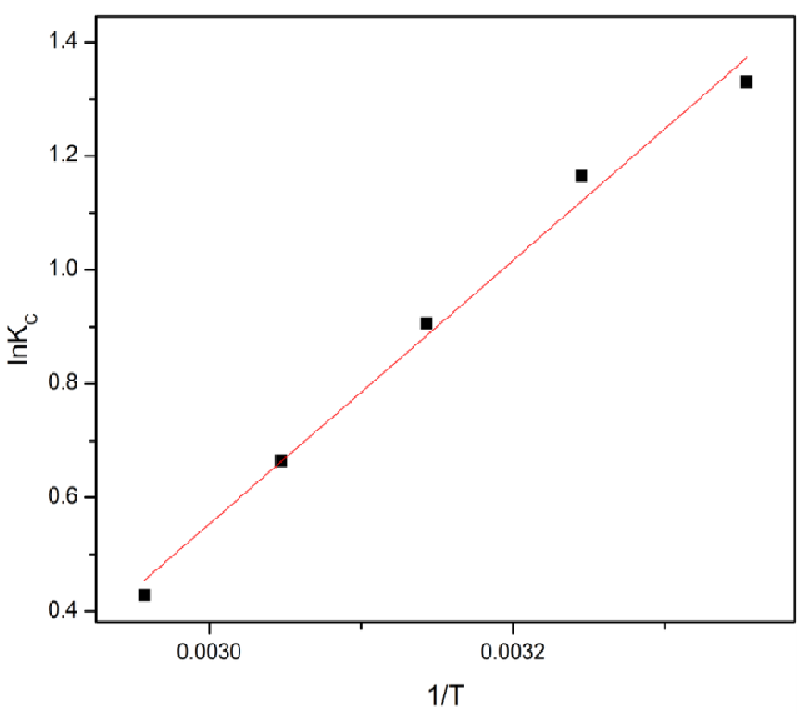

Figure 16: Vant Haff plot for CV dye

\section{CONCLUSION}

The collected mulberry leaves from which powder was prepared in this study demonstrated a high capacity for CV dye adsorption, removing more than $98 \%$ of the dye at an equilibrium adsorption time of 30 minutes, with an equilibrium concentration of $27 \mathrm{mg} / \mathrm{L}$. The experimental data to some extent fit best to the Langmuir isotherm than that of Freundlich and Tempkin isotherm models for linearly regressed data. The Kinetic data fit best to the pseudo- second order kinetic model for linear regressed data while as intraparticle diffusion study reveals that more than one mechanism affected the adsorption process. The calculated thermodynamics parameter like $\Delta \mathrm{G}^{\mathrm{o}}$ and $\Delta \mathrm{H}^{\mathrm{o}}$ shows that the adsorptions of crystal violet $(\mathrm{CV})$ dye onto given adsorbent was favorable, endothermic and exothermic.

\section{ACKNOWLEDGEMENTS}

The authors are thanking full to Maulana Azad College of Arts, Science \& Commerce, Aurangabad Maharashtra, India, and Dr. Babasaheb Ambedkar Marathwada University, Aurangabad, India for providing necessary facilities during the study.

\section{REFERENCES}

Abadian S., Rahbar-Kelishami A., Norouzbeigi R. and Peydayesh M., 2015. Cu(II) adsorption onto Platanus orientalis leaf powder: Kinetic, isotherm, and thermodynamic studies. Res. Chem. Intermed., 41: 7669-7681.

Abd-Elhamid A.I., Emran M., El-Sadek M.H., ElShanshory A.A., Soliman H.M.A., Akl M.A. and Rashad M., 2020. Enhanced removal of cationic dye by eco-friendly activated biochar derived from rice straw. Appl. Water Sci., 10: 45.

Adak A., Bandyopadhyay M. and Pal A., 2005. Removal of crystal violet dye from wastewater by surfactant-modified alumina. Sep. Purif. Technol., 44:139-144.

Bhatnagar A., Kaczala F., Hogland W., Marques M., Paraskeva C.A., Papadakis V.G. and Sillanpaa M., 2014. Valorization of solid waste products from olive oil industry as potential adsorbents for waste pollution control-a review. Environ. Sci. Pollut. Res. Int., 21: 268-298.

Dandge R., Ubale M., Farooqui M. and Rathod S., 2016. Adsorption study for the removal of hazardous dye congo red by biowaste materials as adsorbents. Int. J. Appl. or Innov. Eng. Manag., 


\section{5: 9-16.}

Dar B.A., Saudagar M. and Farooqui M., 2011. Study of isotherms of sorption-desorption of acetic acid from waste water on low cost biomaterials. Int. J. Environ. Sci. Dev. Monit. 2: 17-23.

Dawood S., Sen T.K. and Phan C., 2014. Synthesis and characterization of novel-activated carbon from waste biomass pine cone and its application in the removal of congo red dye from aqueous solution by adsorption. Water Air Soil Pollut., 225: $1-16$.

Freundlich H.M.F.,1906. Over the adsorption in solution. J. Phys. Chem. 57: 385-470.

Guo J.Z., Li B., Liu L. and Lv K., 2014. Removal of methylene blue from aqueous solutions by chemically modified bamboo. Chemosphere, 111: $225-231$.

Hall K.R., Eagleton L.C., Acrivos A. and Vermeulen T., 1966. Pore solid diffusion kinetics in fixed bed adsorption under constant pattern conditions. Ind. Eng. Chem. Fundam. 5: 212-223.

Harrache Z., Abbas M., Aksil T. and Trari M., 2019. Thermodynamic and kinetics studies on adsorption of indigo carmine from aqueous solution by activated carbon. Microchem. J., 144: 180-189.

Hussain S., Abed S. and Farooqui M., 2010. Adsorption studies of Fe (II) on low cost biomaterial. Adv. Appl. Sci. Res., 1: 147-152.

Ijagbemi C.O., Baek M.H. and Kim D.S., 2009. Montmorillonite surface properties and sorption characteristics for heavy metal removal from aqueous solutions. J. Hazard. Mater., 166: 538546.

Jirekar D.B. and Farooqui M., 2013. Adsorption studies of hexavalent chromium ion from aqueous solution using Lenus Esculent (masoor). Int. J. Recent Trends Sci. Technol. ACTRA-INDI., 15-20.

Jirekar D.B., Ghumare P., Fatema S. and Farooqui M., 2015. Adsorption of nickel from aqueous solutions using clean adsorbent as applications of green chemistry. Arab J. Phys. Chem., 2: 7984.

Jirekar D.B., Pathan A.A. and Farooqui M., 2014. Adsorption studies of methylene blue dye from aqueous solution onto Phaseolus aureus biomaterials. Orient. J. Chem., 30: 1263-1269.

Jirekar D.B., Pramila G. and Farooqui M., 2015. Kinetics and isotherm studies on crystal violet dye adsorption onto black gram seed husk. Int. J. ChemTech Res., 7: 427-434.

Jirekar D., Ubale M. and Farooqui M., 2016. Evaluation of adsorption capacity of low cost adsorbent for the removal of congo red dye from aqueous solution. Orbital - Electron. J. Chem., 8: 282287.

Kadam C.A and Farooqui M., 2018. Adsorption equilibrium, kinetics and thermodynamics of malachite green (MG) dye adsorption from aqueous solution on to Bael (Aegle marmelos) bark. Int. J. Green Herbal Chem., 7: 843-852.

Kagalkar A.N., Jagtap U.B., Jadhav J.P., Govindwar S.P. and Bapat V.A., 2010. Studies on phytoremediation potentiality of Typhonium flagelliforme for the degradation of brilliant blue R. Planta, 232: 271-285.

Kaur H., 2009. Spectroscopy, fifth Edition. ISBN: 97881-8398-690-0.

Khan F.A., Ahad A., Shah S.S. and Farooqui M., 2021. Adsorption of crystal violet dye using Platanus orientalis (chinar tree) leaf powder and its biochar: Equilibrium, kinetics and thermodynamics study. Int. J. Environ. Analyt. Chem. (GEAC).

Lagergren S., 1898. Zur theoric der sogenannten adsorption geloster stoffe (about the theory of so-called adsorption of soluble substances), Kungliga Svenska Vetenskapsakademiens Handlingar., 24: 1-39.

Lairini S., El Mahtal K., Miyah Y., Tanji K., Guissi S., Boumchita S. and F. Zerrouq., 2017. The adsorption of crystal violet from aqueous solution by using potato peels (Solanum tuberosum): equilibrium and kinetic studies. JMES., 8: 3252-3261.

Langmuir I., 1918. The adsorption of gases on plane surfaces of glass, mica and platinium. J. Am. Chem. Soc. 40: 1361-1403.

Menkiti M.C., Aniagor C., Agu C. and Ugonabo V.I., 2018. Effective adsorption of crystal violet dye from an aqueous solution using lignin-rich isolate from elephant grass. Water Conserv. Sci. 
Eng., 3: 33-46.

Noorimotlagh Z., Mirzaee S.A., Martinez S.S., Alavi S., Ahmadi M. and Jaafarzadeh N., 2019. Adsorption of textile dye in activated carbons prepared from DVD and CD wastes modified with multi-wall carbon nanotubes: Equilibrium isotherms, kinetics and thermodynamic study. Chem. Eng. Res. Des., 141: 290-301.

Pathania D., Sharma S. and Singh P., 2017. Removal of methylene blue by adsorption onto activated carbon developed from Ficus carica bast. Arab. J. Chem. 10: S1445-S1451.

Pavia D.L., Lampman G.M. and Kriz G.S., 196. Introduction to spectroscopy, 2nd ed. Saunders Golden Sunburst Ser. New York.

Rangabhashiyam S., Anu N. and Selvaraju N., 2013. Sequestration of dye from textile industry wastewater using agricultural waste products as adsorbents. J. Environ. Chem. Eng., 1: 629-641

Sabnis R.W., 2010. Handbook of biological dyes and stains: synthesis and industrial applications, John Wiley Sons, Hoboken.

Santos S.C.R. and Boaventura R.A.R., 2016. Adsorption of cationic and anionic azo dyes on sepiolite clay: equilibrium and kinetic studies in batch mode. J Environ Chem Eng., 4: 1473-1483.

Shah S.S., Kumar D., Sharma T., Kapoor K.K. and Bamezai R.K., 2021. Experimental and computational studies on the removal of crystal violet dye from aqueous solution using juglans regia leaves treated with acetic acid and Larginine. Int. J. Environ. Analyt. Chem. (GEAC).

Sine P., 2003. Synthetic dyes. west ed. Rajat publications, New Delhi.

Taher A., Mohsin M., Farooqui M. and Farooqui M., 2012. Studies on the isotherms, kinetics and thermodynamics of adsorption of crystal violet on low cost materials. J Adv Sci. Res. 3: 36-44.

Tan I.A.W., Ahmad A.L. and Hameed B.H., 2008. Adsorption of basic dye on high-surface area activated carbon prepared from coconut husk: equilibrium, kinetic and thermodynamic studies. J. Hazard Mater., 154: 337-346.

Temkin M. and Pyzhev V., 1940. Kinetics of ammonia synthesis on promoted iron catalyst. Acta Phys. Chim. U.S.S.R., 12: 327-356.

University of Colorado., 1985. Table of characteristic IR absorptions. http://orgchem.colorado.edu/ spectroscopy/specttutor/irchart.pdf.

Weber W.J. and Morris J.C., 1963. Kinetics of adsorption on carbon from solution. J. Sanit. Eng. Div. Proceed. Am. Soc. Civ. Eng., 89: 31-59.

Wellesley college., 1875. Table 1: Principal IR absorptions for certain functional groups. http://academics.wellesley.edu/chemistry/chem2 11lab/orgo_lab_manual/appendix/instruments/in frared spec/chem $211 \% 20 I R \% 20$ Lit $\% 20$ Value $\%$ 20table.pdf 